\title{
The 2005 Lake Malawi Scientific Drilling Project
}

\author{
by Christopher A. Scholz, Andrew S. Cohen, Thomas C. Johnson,
}

\section{Introduction}

Lake Malawi, located in the southern part of the East African Rift Valley, is one of the world's largest, deepest $(700 \mathrm{~m})$ and oldest (>7 Ma) lakes and is renowned for its biodiversity, especially its unique ecosystem including hundreds of species of fish and invertebrates found nowhere else on Earth. Geologists and paleolimnologists have sought for several decades to establish a high-resolution East African geologic and climatic history through scientific drilling of the East African Rift Valley lakes. The Lake Malawi Scientific Drilling Project reached this goal by acquiring more than $623 \mathrm{~m}$ of core at two sites-one highresolution site and one deep site extending back to 1.5 Ma. A total of seven holes, including one hole in $600 \mathrm{~m}$ water depth that reached a subbottom depth of $380 \mathrm{~m}$, were cored with an

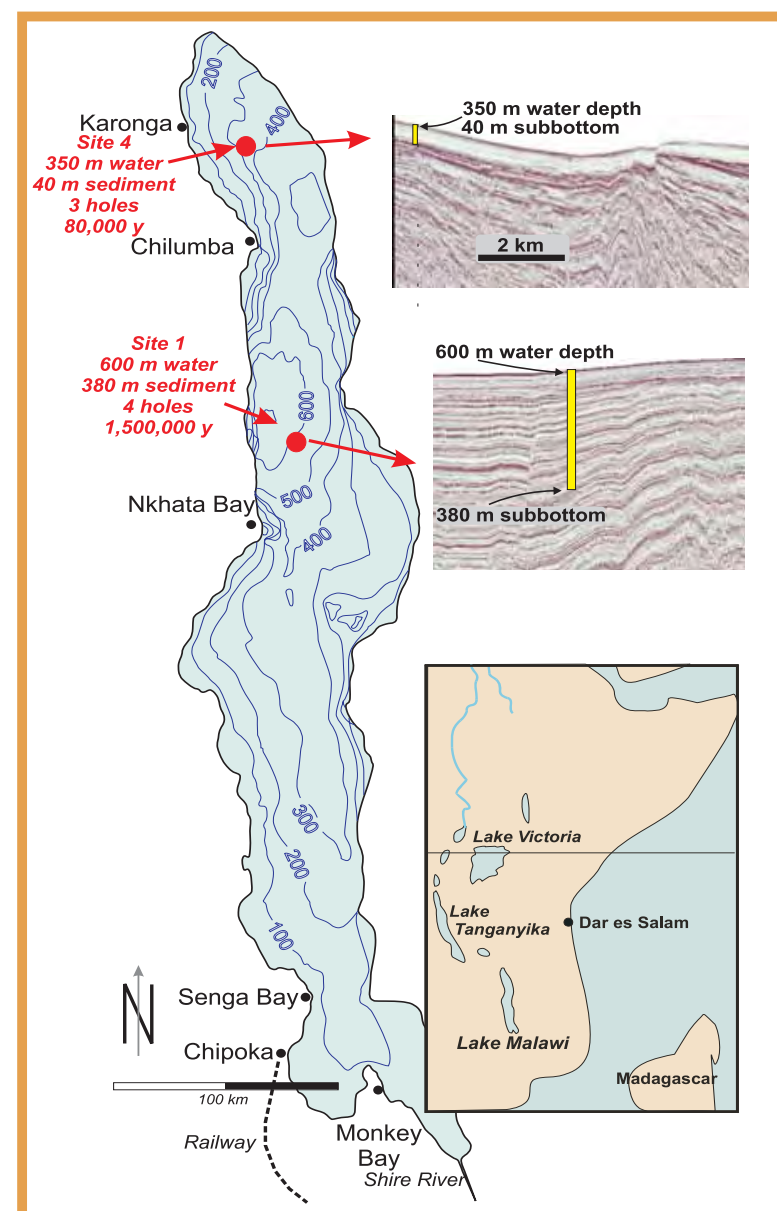

Figure 1. Bathymetry of the Lake Malawi Rift, with drill site locations and seismic profiles. average recovery of $92 \%$. The high-resolution site was triplecored and extends back $\sim 80 \mathrm{ky}$. The deep site was double cored in the upper part that covers the past $200 \mathrm{ky}$ and then single-cored to its target depth of $380 \mathrm{~m}$ (Figs. 1 and 2).

\section{The Importance of the Continental Tropics in the Global Climate System}

The climate of tropical East Africa shows strong seasonal variability in rainfall and wind regime. Seasonal variability in temperature is minor in comparison but still significant in its impact on lake circulation dynamics. East African rainfall is strongly influenced by the seasonal migration of the Intertropical Convergence Zone (ITCZ) across the equator. The passage of the ITCZ gives rise to heavy rains on the landscape. The moisture is derived from both the Atlantic and Indian Oceans in monsoonal circulation associated with summer heating of the continental interior. Regions located near the equator experience two rainy seasons per yearlong rains from March to May, and short rains from October to November, while areas farther from the equator experience only the southernmost or northernmost extent of the ITCZ and a single rainy season in the year. Lake Malawi experiences the latter case, as the rainy season occurs during the hottest months of the austral summer, from December to February.

To understand paleoclimate on a global scale, it is essential to understand the history of tropical climatic change, and especially variations from the modern climatology described above. Ocean sediment cores from offshore North Africa

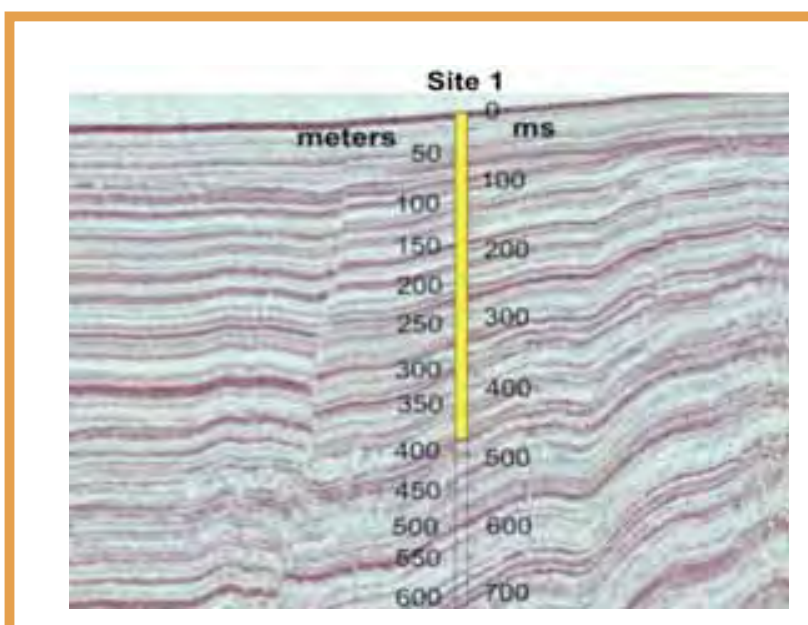

Figure 2. Airgun seismic profile with penetration at Site 1. 


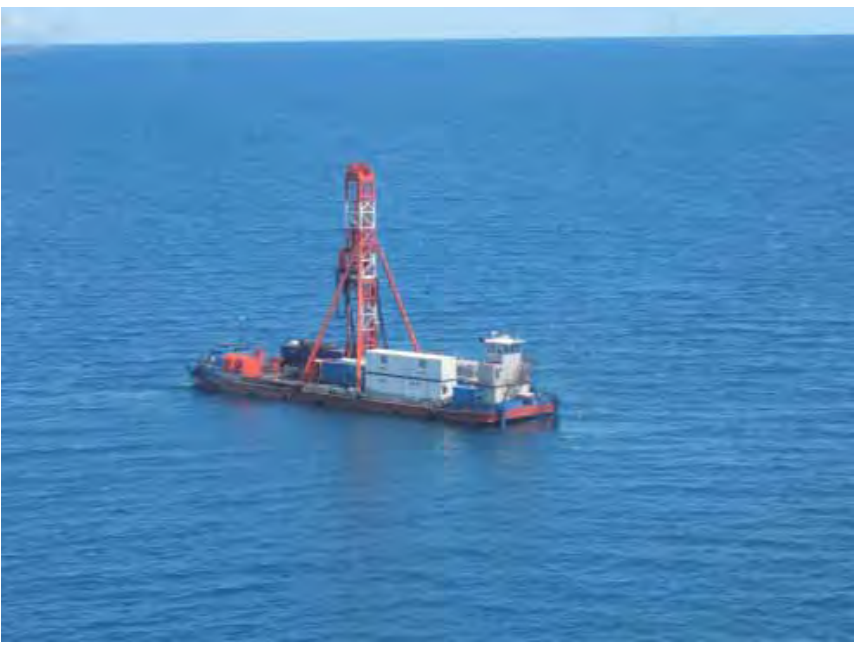

Figure 3. The Viphya drilling barge in central Lake Malawi.

have shown that African climate responds to insolation change on orbital (Milankovitch) timescales. The timing, controls and behavior of this vast tropical region, however, have been interpreted primarily from data from Ocean Drilling Program cores that integrate the signal from nearly half the continent (deMenocal, 1995; Clemens et al., 1996). The new drill cores from Lake Malawi sample an important region of the southern hemisphere continental tropics not previously sampled at a decadal to century scale beyond $\sim 25 \mathrm{ka}$.

The key science questions addressed by the Lake Malawi drilling include the following.

- What is the direction, magnitude, and timing of effective moisture, wind and temperature change of this southern tropical setting, on a millennial scale, during the past two glacial-interglacial cycles?

- Do the observed shifts coincide in a consistent manner with sea-surface temperature (SST) variability in the tropical oceans, or with the North Atlantic thermohaline circulation?

- What is the lake level history of Malawi, and how does it compare with the methane record of the polar ice cores, which is interpreted to be a globally averaged measure of tropical moisture on the continents?

- Does the observed evidence for abrupt climate change in Lake Malawi and other parts of East Africa coincide with known events from other regions on Earth, e.g., Heinrich or Dansgaard-Oeschger events? What are the direction, duration and magnitude of these changes?

- What was the tropical climate behavior during earlier periods of global warmth (e.g., Marine Isotopic Stage 5 e, or alternatively MIS 11), and how abruptly did these periods begin and end?

- Did the climate of this site in the southern tropics respond only to changes in low-latitude precessional insolation (23-19 ky) or also to high-latitude, icevolume (100 ky and $41 \mathrm{ky}$ ) forcing in the last part of the Pleistocene?
- How did Pleistocene climate change impact early modern human evolution and population dynamics?

- How do the controls of climate impact species evolution and ecosystem change in large, ancient lakes?

\section{Logistical and Engineering Challenges of Drilling in Interior Africa}

Lake Malawi is $560 \mathrm{~km}$ long, $40 \mathrm{~km}$ wide, and situated $\sim 400 \mathrm{~km}$ from the Indian Ocean. No navigable waterways connect this vast lake to the ocean; however, the Lake Malawi Scientific Drilling Project took advantage of an existing fuel barge Viphya (Fig. 3) operated by Malawi Lake Services as the drilling platform. Under the direction of the University of Rhode Island, the project's general contractor, various engineering components were procured in Europe, North America and South Africa and shipped to the local shipyard in Monkey Bay in southern Lake Malawi. During the second half of 2004, Lengeek Vessel Engineering of Halifax supervised significant modifications of the barge, including the installation of a moon pool, containerized living quarters and a dynamic positioning system. Initial underway trials were conducted in December 2004, and the Seacore C-100 drilling rig was installed in February 2005. Drilling tools run by Drilling, Observation and Sampling of the Earth's Continental Crust Inc. (DOSECC), were used in the project. They included a hydraulic piston corer and extended nose sampler that were fitted with a custom bottom-hole assembly.

Drilling commenced in late February 2005, after extensive testing and modification of equipment. Operations involved a team of twenty-six persons aboard the drilling barge, including nine drillers and a team of thirty persons onshore and on support boats as logistical support staff (Fig. 4). The onshore team also undertook an extensive outreach effort, visiting many Malawian secondary schools and government offices and informing them of the project.

Various technological difficulties that arose right from the start were ultimately overcome by a resourceful team of

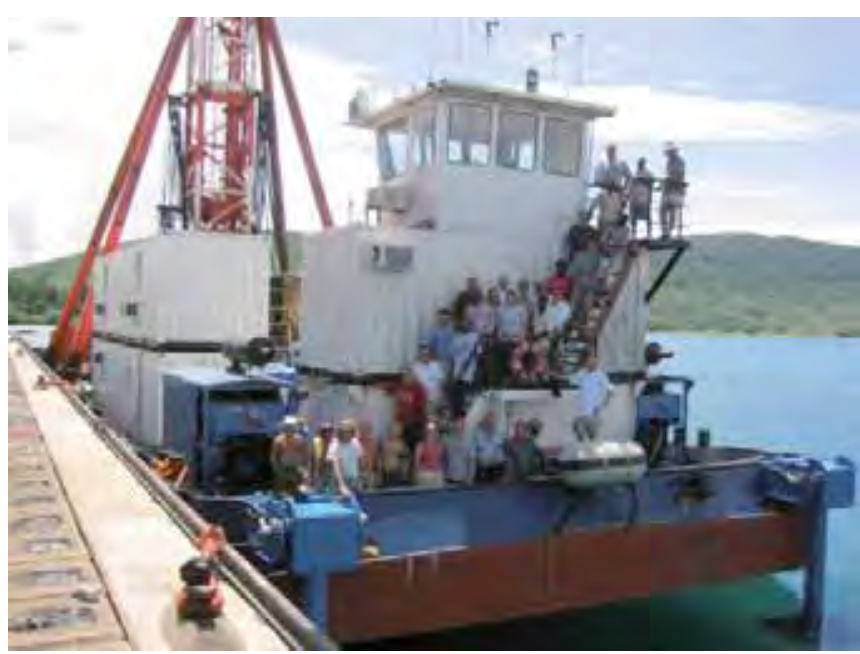

Figure 4. The drilling project team. 


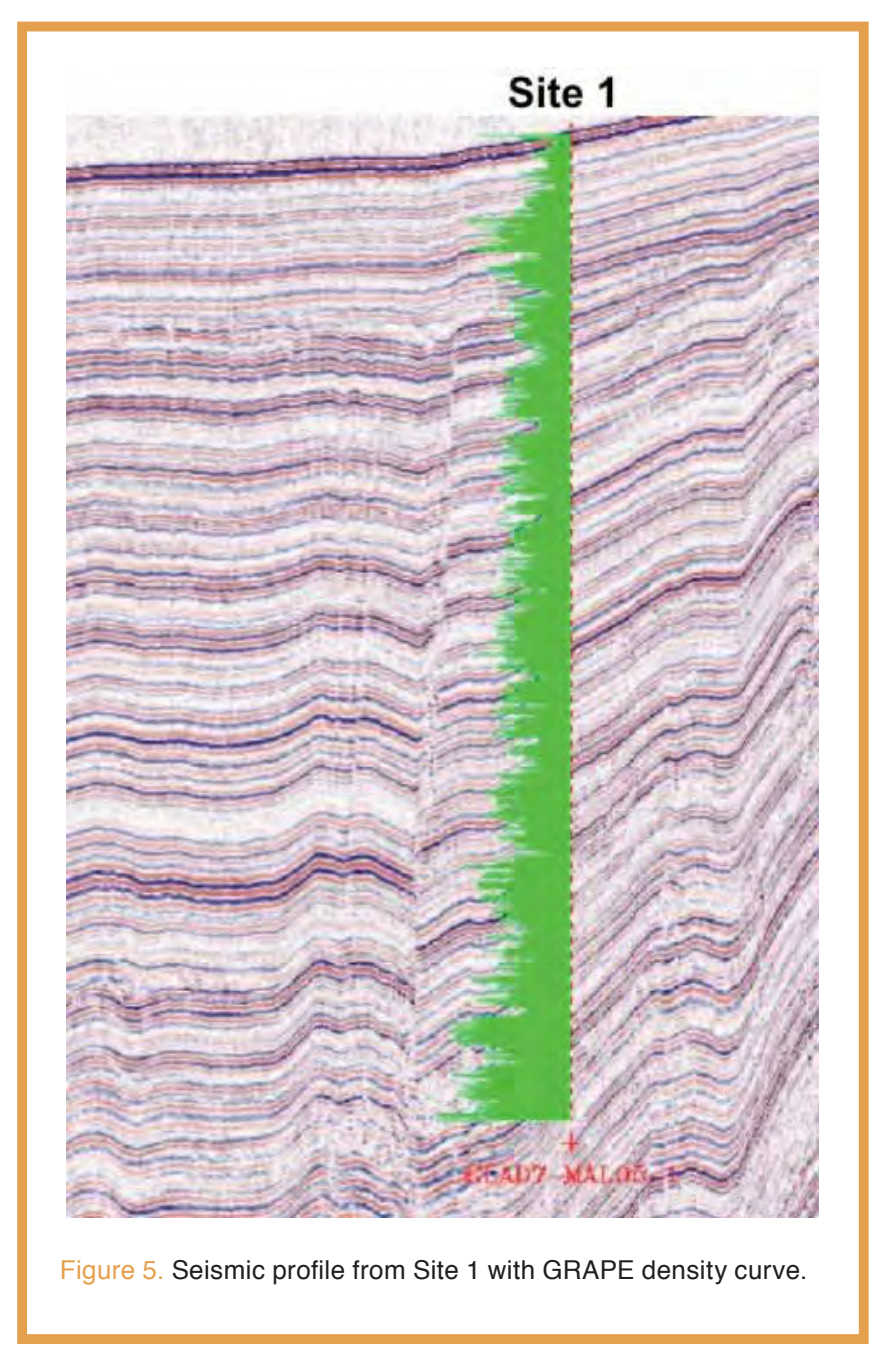

engineers and technicians, and routine drilling operations finally began on 9 March 2005. Drilling then commenced for ten days at the deep site, located at a water depth of approximately $600 \mathrm{~m}$ in the central basin of Lake Malawi.

\section{Preliminary Results}

Whole-core measurements of recovered samples were made using the International Continental Scientific Drilling Program (ICDP) GEOTEK logging system, based at the science station in Chilumba, Malawi. Core data were comlemented through gamma-ray downhole logging by the operational support group of the ICDP (Fig. 5). Initial core description efforts are underway at the National Lacustrine Core Repository (LacCore) based in Minneapolis, Minn., U.S.A. Initial inspection of the cores reveals the presence of laminated and homogenous diatomaceous mud, cemented siltstone, volcanic ash horizons and fine-grained, well-sorted sands at the base of holes at both sites. Preliminary results indicate that lake levels fell and rose hundreds of meters on numerous occasions over the time interval represented by the recovered cores. Geochronological analyses are underway utilizing paleomagnetic data and a variety of radiometric dating methods. Preliminary results suggest that the deep site in the central basin is about 1.5 million years old at its base and that the holes in the north basin bottom out in shoreface sand deposits are about 80,000 years old. Wholecore measurements on physical properties show pronounced 100-ky cyclicity extending over the length of the longest record, suggesting that the level of Lake Malawi has fluctuated dramatically over the past million years.

\section{Acknowledgements}

We thank the people and government of Malawi for permission to conduct this research, and in particular the Geological Survey of Malawi for local assistance and participation. Numerous individuals from key contractors worked tirelessly to complete the program. We thank the U.S. National Science Foundation (NSF) Earth System History and Paleoclimate Programs, and the ICDP for financial support. As part of the project, funding from both agencies was used to acquire a portable dynamic positioning (DP) system for use by drilling projects that demand alternative platform technologies.

\section{References}

Clemens, S.C., Murray, D.W., and Prell, W.L., 1996. Nonstationary phase of the Plio-Pleistocene Asian monsoon. Science, 274:943B948. doi:10.1126/science.274.5289.943

deMenocal, P.B., 1995. Plio-Pleistocene African climate. Science, 270:53B59.

\section{Authors}

Christopher A. Scholz, Department of Earth Sciences, 204 Heroy Geology Laboratory, Syracuse University, Syracuse NY 13244, U.S.A., e-mail: cascholz@syr.edu

Andrew S. Cohen, Department of Geosciences, University of Arizona, Gould-Simpson Building \#77, 1040 East 4th St., Tucson, AZ 85721, U.S.A.

Thomas C. Johnson, Large Lakes Observatory and Department of Geological Sciences, University of MinnesotaDuluth, Duluth, MN 55812, U.S.A.

John W. King and Kathryn Moran, University of Rhode Island Graduate School of Oceanography, South Ferry Road, Narragansett, RI 02882-1197, U.S.A.

\section{Related Web Links}

http://malawi.icdp-online.org http://malawidrilling.syr.edu

\section{Figure Credits}

All figures courtesy of the ICDP and the Lake Malawi Scientific Drilling Project. 